\title{
ONLINE IMPRESSIONS ON E-HAILING SERVICES: A STUDY ON Positive AND NeGative SENTIMENTS ON GRAB MALAYSIA AND GO-JEK INDONESIA ON TWITTER PLATFORM
}

\section{Emily Chow Yan Chi ${ }^{\star}$}

Faculty of Accountancy and Management Universiti Tunku Abdul Rahman, Selangor Malaysia ycchow_614@hotmail.com

\section{Goh Hong Lip}

Faculty of Accountancy and Management Universiti Tunku Abdul Rahman, Selangor Malaysia

gohhl@utar.edu.my

\section{Lim Yee Wui}

Faculty of Accountancy and Management Universiti Tunku Abdul Rahman, Selangor Malaysia ywlim@utar.edu.my

\section{Lai Siew Fong}

Faculty of Accountancy and Management Universiti Tunku Abdul Rahman, Selangor Malaysia

laisf@utar.edu.my

\section{Alexander Tay Guan Meng}

Faculty of Accountancy and Management

Universiti Tunku Abdul Rahman, Selangor

Malaysia

taygm@utar.edu.my

*Corresponding author's Email: ycchow_614@hotmail.com

Peer-review under responsibility of 4th Asia International Multidisciplinary Conference 2020 Scientific Committee http://connectingasia.org/scientific-committee/ (C) 2020 Published by Readers Insight Publisher, lat 306 Savoy Residencia, Block 3 F11/1,44000 Islamabad. Pakistan, editor@ readersinsight.net 


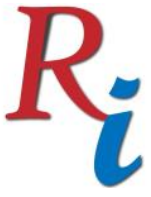

Asia Proceedings of Social Sciences

(APSS)

www.readersinsight.net/APSS

\section{A b s t r a c t}

The presence of mobile-internet has led to the emergence of the e-hailing industry. As the ehailing services usage increased, it led riders to share their opinions or discontent after indulging in the services. Therefore, in this study, online sentiments on social media (Twitter) with specific keywords mentioned, were examined to identify the rider opinions towards the ehailing services in both Malaysia and Indonesia. Service Quality (SERVQUAL) model was used as the foundation to examine the service quality offered by the e-hailing service providers. The dimensions included were: 'Availability', 'Accessibility', 'Information', 'Comfort', 'Safety', and the additional dimension of 'Price'. All the data (tweets) collected were classified into either a positive or negative sentiment, and to respective dimensions manually, by referring to keywords. The results revealed that all the dimensions show a negative trend in both countries. 'Comfort' and 'Availability' was ranked the first in Malaysia and Indonesia respectively, and the results shown were due to riders demanded an e-hailing service that is available anywhere and anytime when they need it. The study results provide a strong reference to practitioners to improve on their service quality and allowed to identify which dimensions were concerned the most by the riders in both countries.

\section{Rese a r ch H i g h I g h t s}

- The model proposed in this study streamlined the SERVQUAL model into a model that better suits the e-hailing industry.

- The model proposed consists of an additional dimension 'Price', which differ from those previous studies on service quality.

- The research identified the service dimension most concerned by the riders in Malaysia and Indonesia. 


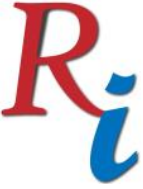

Asia Proceedings of Social Sciences

(APSS)

www. readersinsight.net/APSS

\section{Graphical A bstract}

\begin{tabular}{|l|}
\hline Parasuraman et al. (1985) \\
- Reliability \\
- Responsiveness \\
- Access \\
- Courtesy \\
- Communication \\
- Securility \\
- Understanding/Knowing \\
the Customer \\
- Tangibles \\
\hline
\end{tabular}
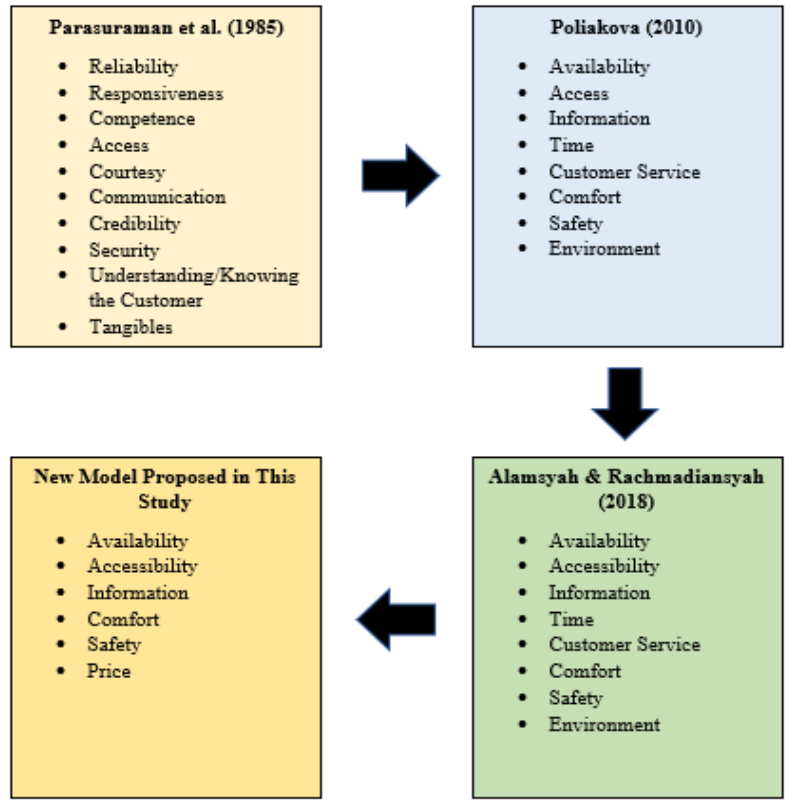

Fig. 1: The Proposed Transportation Service Quality Model in This Study

\section{Research Objectives}

The general objective of this study is to analyze the online sentiments regarding the customer satisfaction on e-hailing services in both Malaysia and Indonesia by analyzing then classify the tweets collected using Transportation Service Quality Model (Alamsyah \& Rachmadiansyah, 2018), which adapted and adopted from both research conducted on SERVQUAL model (Parasuraman et al., 1985) and Customer Satisfaction Index (Poliakova, 2010).

\section{Specific Objectives}

1. The purpose of this study is to identify the online sentiment regarding rider's satisfaction on e-hailing services in both Malaysia and Indonesia. (i.e. positive or negative sentiment)

2. The purpose of this study is to identify the differences in the online sentiment regarding rider's satisfaction on e-hailing services between both Malaysia and Indonesia.

By conducting this study, service providers can understand the user opinions towards the ehailing service in both Malaysia and Indonesia. The result of this study may also serve as a reference for various service providers to improve their service quality and identify which dimension concerned the most by the users. Moreover, the new model proposed in this study streamlined the previous model and provide a new perspective of service quality model specifically for the e-hailing industry. 


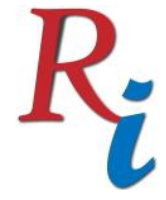

Asia Proceedings of Social Sciences

(APSS)

www.readersinsight.net/APSS

\section{Methodology}

This study is a mixed-method research, which is the combination of qualitative and quantitative study. To analyze the online sentiments, any tweets related to Grab Malaysia and Go-Jek Indonesia were collected from Twitter from two major sources, 1) Go-Jek (@gojekindonesia), and 2) Grab's (@grabMY) official Twitter account. All the relevant tweets were collected by screening through the content manually then classified into the six major dimensions proposed in this study. All the measuring dimensions were developed through a broad literature review.

The classification of tweets consists of two stages. All the tweets were first classified into either a positive or negative sentiment, which were determined manually according to the emoticons, pictures, image attached, or any vulgar wordings. However, for the simplicity, only positive and negative sentiments were captured in this study. After classifying the tweets into a positive or negative sentiment, the tweets then categorized into the six dimensions proposed in this study based on the similar meaning, keywords, or if the content of the tweets is related to the features or description of the dimensions. Statistical Package for Social Science (SPSS) was used to further process and analyze the tweets collected to obtain results such as frequencies and possible combination of dimensions.

\section{Results}

A total of 688 tweets were collected, where $573(83.28 \%)$ are negative and $115(17.72 \%)$ are positive sentiments. Out of 688 tweets collected via Twitter and keywords, 335 (48.69\%) tweets were collected for Grab Malaysia, where 293 (87.46\%) tweets are negative, and the remaining $42(12.54 \%)$ are positive. On the other hand, $353(51.31 \%)$ tweets were collected for Go-Jek Indonesia, which consists of 280 (79.32\%) negative tweets and $73(20.67 \%)$ positive tweets $143(20.78 \%)$ out of 688 tweets consists of 2 or more dimensions per tweet. $120(83.92 \%)$ out of 143 tweets commented are negative, while $23(16.08 \%)$ tweets are positive. However, 842 sentiments were identified in total because there are tweets with sentiments on various dimensions.

According to the data collected, Relative Importance Index (RII) for each dimension in both countries were calculated. 'Comfort' and 'Availability' were ranked the first place, which shows the dimension that riders concerned the most for both Malaysia and Indonesia respectively. Furthermore, the effect of Implementation of New E-hailing Regulation in Malaysia was studied, where the number of overall positive and negative sentiments were compared between January to June 2019 and July to September 2019. However, a slight decrease in the number of sentiments collected were shown after the implementation of new regulation. 


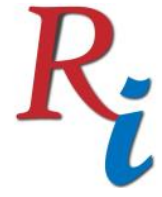

Asia Proceedings of Social Sciences

(APSS)

www.readersinsight.net/APSS

\section{Findings}

Among all the possible combination of dimensions, 'Availability' and 'Comfort' shows the highest negative and positive sentiments. When customer feels comfort in terms of availability and ease of use the e-hailing services, the higher the positive sentiments. A research conducted by Poliakova (2010) proves that the greater the comfort provided, the higher the customer satisfaction index

Price' dimension shows the most significant difference between Malaysia and Indonesia. This is because Grab Malaysia uses car while Go-Jek Indonesia mainly using motorbike in their service. Thus, the price of using a car is relatively higher than the motorbike.

\section{Acknowledgement}

This study has been completed successfully with the assistance and guidance from my supervisor, Dr Goh Hong Lip. I would like to thank Dr Goh for his effort and time in guiding and providing precious advice to me on conducting this challenging study. Besides, I would like to thank Universiti Tunku Abdul Rahman (UTAR) Institute of Postgraduate Studies and Research (IPSR) for providing us the research grant (IPSR/RMC/UTARRF/2019-C1/G05) to complete this study.

\section{References}

Alamsyah, A., \& Rachmadiansyah, I. (2018, March). Mapping online transportation service quality and multiclass classification problem solving priorities. In Journal of Physics: Conference Series (Vol. 971, No. 1, p. 012021). IOP Publishing.

Parasuraman, A., Zeithaml, V. A., \& Berry, L. L. (1985). A conceptual model of service quality and its implications for future research. Journal of marketing, 49(4), 41-50.

Poliakova, A. (2010). Customer satisfaction index with a quality of service in public mass transport. Transp. Commun, 2, 43-49.

Author's Biography

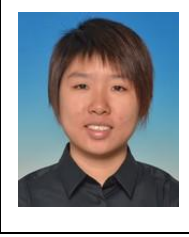

Emily Chow Yan Chi is an undergraduate student who is currently pursuing a Bachelor's Degree in International Business (Hons) at Universiti Tunku Abdul Rahman (UTAR), Malaysia. 